\title{
Raman spectra, normal modes and disorder in monoclinic tridymite and its higher temperature orthorhombic modification
}

\author{
Kuniaki KIHARA*, Tadayuki HiRose* and Keiji SHINODA** \\ "Department of Earth Sciences, Kanazawa University,Kakuma, Kanazawa 920-1192, Japan \\ ** Department of Geosciences, Osaka City University, Sugimoto 3-3-138,Sumiyoshi, Osaka 558-8585, Japan
}

\begin{abstract}
The experimental Raman spectra of monoclinic tridymite and its higher temperature orthorhombic modification were successfully simulated with valence force fields applied to the $\mathrm{X}$-ray determined structural parameters. The normal modes contributing to the corresponding Raman peaks in both the phases share essentially the same types of atomic displacements or bond deformations. In the modes with the wave numbers between 100 and $600 \mathrm{~cm}^{-1}$, predominant are the librations of $\mathrm{Si}^{-} \mathrm{O}^{-} \mathrm{Si}$ planes around $\mathrm{Si}-\mathrm{Si}$ lines, being followed by bending of $\mathrm{Si}^{-} \mathrm{O}^{-} \mathrm{Si}$ or $\mathrm{O}^{-} \mathrm{Si}^{-} \mathrm{O}$ angles. The librational motions of $\mathrm{SiO}_{4}$ units around $\mathrm{Si}$ appear in the modes below 100 $\mathrm{cm}^{-1}$. Significant bond stretching and compression appear in the modes with wave numbers higher than 700 $\mathrm{cm}^{-1}$ : the deformations are classified into 10 types, 7 for $\mathrm{Si}-\mathrm{O}-\mathrm{Si}$ and 3 for $\mathrm{SiO}_{4}$. Some modes in the highest frequency group between 1150 and $1250 \mathrm{~cm}^{-1}$ show symmetric bond stretching and compression of $\mathrm{SiO}_{4}$ units, while those between 1000 and $1150 \mathrm{~cm}^{-1}$ antisymmetric stretching and compression of $\mathrm{Si}-\mathrm{O}-\mathrm{Si}$.

A low-frequency normal mode is identified to have the polarization vectors of $\mathrm{O}$ atoms, which are nearly parallel with the largest principal axes of their thermal ellipsoids. A disorder model is presented to account for the extremely large mean square displacements of $\mathrm{O}$ atoms, and a possibility is suggested for the normal mode to boost the hopping of the $\mathrm{SiO}_{4}$ units between the two orientations.
\end{abstract}

Keywords: Tridymite, Raman spectra, Disorder, Atomic displacements, Lattice dynamics

\section{INTRODUCTION}

There have been a large number of studies reported about the tridymite phases of $\mathrm{SiO}_{2}$, but no successful result of lattice dynamical calculations has been reported so far. In applying their valence force field (Echepare et al., 1974) to $\alpha$-cristobalite, Echepare et al. (1978) succeeded to attain a reasonable fit with Raman spectroscopic data. These authors also applied their force field to tridymite, comparing with Raman spectroscopic data measured for a powdered specimen at room temperature. They were apparently suffered from at least two severe problems. Firstly, the specimen used was not identified among the meta-stable phases or a mixture of those. Secondly, the crystal structures of those phases were not established at that time. After all, the lattice dynamical aspects in the phases of tridymite have been not yet established.

K. Kihara, kuniaki@kenroku.kanazawa-u.ac.jp Corresponding author
Monoclinic tridymite (MC) is one of the meta-stable phases appearing at low temperatures including room temperature. MC from a fired silica brick shows a series of successive transformations with increasing temperatures, $\mathrm{MC}-\mathrm{OP}-\mathrm{OC}-\mathrm{HP}$, where $\mathrm{HP}$ is the highest-symmetry hexagonal phase of tridymite, and OP and $\mathrm{OC}$ are both orthorhombic (Kihara, 1977). (The nomenclature of Nukui and Nakazawa, 1978 and 1980 is used through this paper.) For OP, which is the $(3 \times 1 \times 1)$ superstructure of OC, Kihara $(1977$; 1995) suggested a possibility of oxygen disorder in taking account of the large values of oxygen mean square displacements (abbreviated as MSD), and Xiao et al. (1993) provided an NMR evidence supporting dynamic disorder of $\mathrm{O}$ atoms in the high temperature forms of tridymite including OP. According to the latter authors, the frequencies of the dynamic disorder of $\mathrm{O}$ atoms are greater than the order of $\mathrm{KHz}$ for at least $\mathrm{OC}$ and HP.

In the ideal tridymite structure, which may be represented by the mean positions of atoms in $\mathrm{HP}, \mathrm{SiO}_{4}$ units 


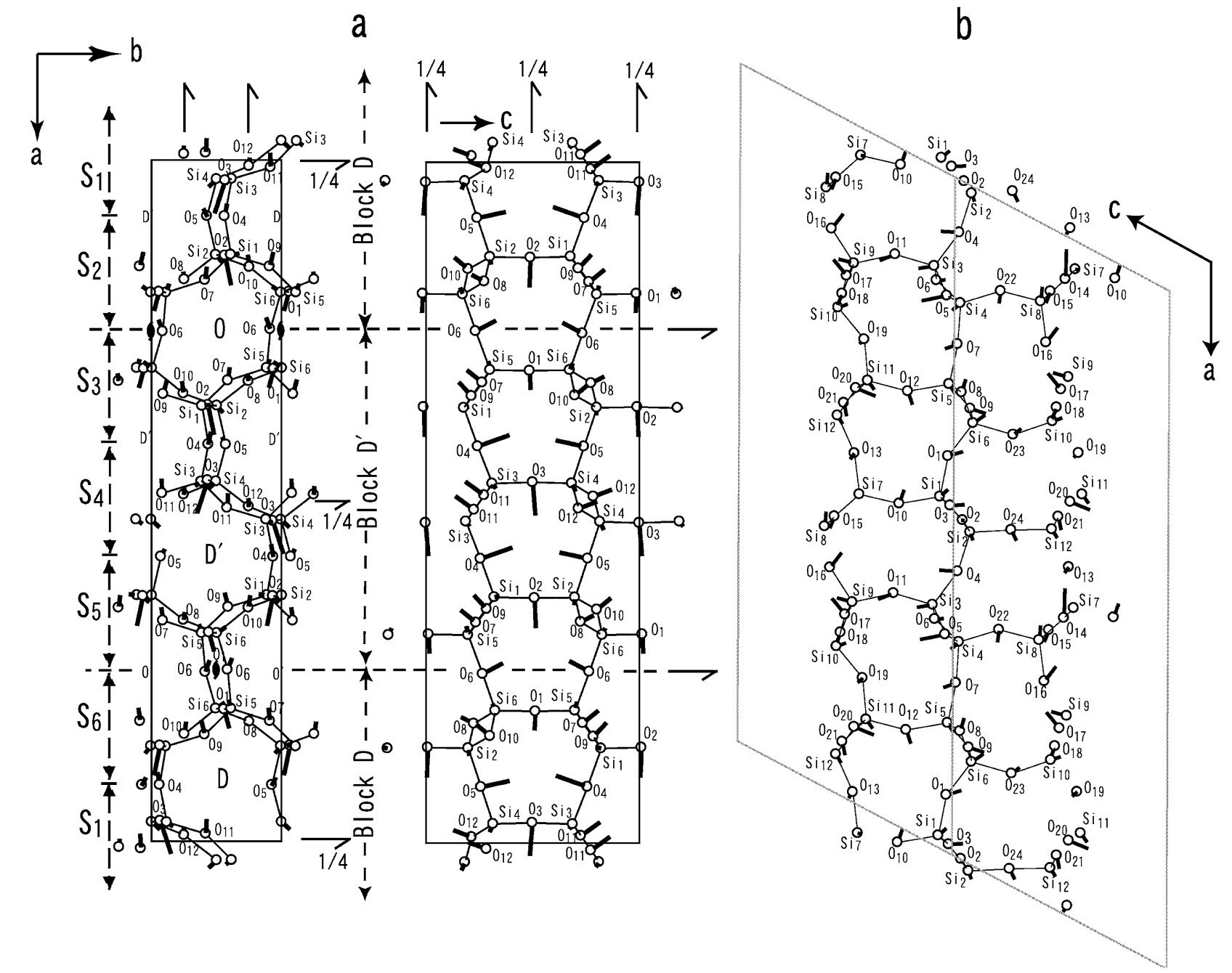

b

Figure 1. Structures of orthorhombic (OP) and monoclinic (MC) tridymites, and identification of atoms. Atoms are identified with running numbers attached. a. Orthorhombic tridymite, in space group $P 2_{1} 2_{1} 2_{1}$, projected on (001) in the left half and on (010) in the right half. The cell contains 18 (6 Si and $12 \mathrm{O}$ ) independent atoms, all on the general positions (Hirose et al., 2004). Calculated atomic polarization vectors in the $B_{3}$ mode at $74.9 \mathrm{~cm}^{-1}$ are indicated. Symbols $S_{1}$ to $S_{6}$ indicate slabs stacked perpendicularly to [100] to form the unit cell. Symbols D and $\mathrm{D}^{\prime}$ show that the ditrigonal deformations of six-membered rings occur in stacked three slabs, $\mathrm{S}_{3}-\mathrm{S}_{4}-\mathrm{S}_{5}\left(\right.$ block $\left.\mathrm{D}^{\prime}\right)$ and $\mathrm{S}_{6}-\mathrm{S}_{1}-\mathrm{S}_{2}($ block $\mathrm{D})$, respectively. Two-fold screw axes are indicated except some perpendicular to the paper. b. Monoclinic tridymite, in space group Aa, projected on (010). The unit-cell contains $36(12 \mathrm{Si}$ and $24 \mathrm{O})$ independent atoms, on all general positions. Calculated atomic polarization vectors in a mode (spec. $\mathrm{A}^{\prime}$ ) at $200.6 \mathrm{~cm}^{-1}$ are indicated to represent low frequency modes in MC.

join each other by sharing their corner $\mathrm{O}$ atoms to form the three-dimensional framework of six-membered rings. For the convenience of describing the thermal vibrational behaviors, the three $\mathrm{O}$ atoms of $\mathrm{a} \mathrm{SiO}_{4}$ in a plane of sixmembered rings are distinguished from the fourth $\mathrm{O}$, which is off the plane: the former is called as the basal $\mathrm{O}$ atoms and the latter the apical $\mathrm{O}$ atom. $\mathrm{The}^{\mathrm{SiO}}{ }_{4}$ units orient upward and downward alternately in the six-membered rings to form the tridymite layers, which are stacked each other by sharing the apical $\mathrm{O}$ atoms to form the hexagonal channels along the $c^{-}$axis. Looking down the tridymite layer of MC or OP along the pseudohexagonal $c^{-}$ axis, the six-membered rings are seen to be distorted into a ditrigonal shape and an oval one, denoted as $\mathrm{D}$ (or $\mathrm{D}^{\prime}$ in another orientation) and $\mathrm{O}$ (or $\mathrm{O}^{\prime}$ ), respectively. The projections of the unit cells of OP (space group $P 2_{1} 2_{1} 2_{1}$ ) on (001) and (010), and MC (Aa) on (010) are shown in Figure 1 ( $\mathrm{a}$ and $\mathrm{b}$ ), respectively, where 36 (12 Si and $24 \mathrm{O}$ ) and 18 (6 Si and $12 \mathrm{O}$ ) symmetry-independent atoms are identified with the numbers attached. The $\mathrm{O}$ atoms, $\mathrm{O}_{1}, \mathrm{O}_{2}$ and $\mathrm{O}_{3}$ in $\mathrm{OP}$, and $\mathrm{O}_{10}, \mathrm{O}_{11}, \mathrm{O}_{12}, \mathrm{O}_{22}, \mathrm{O}_{23}$ and $\mathrm{O}_{24}$ in $\mathrm{MC}$ are the apical ones, and the remaining $\mathrm{O}$ atoms are the basal ones. However, the two structures are different each other in the ways for the distorted six-membered rings to stack along the pseudohexagonal $c$-axis: the same type of distortion continues along that axis in OP, but not in MC. 
According to Hirose et al. (2005), the unit cell of the OP structure can be seen as a stacking of the six slabs $\left(\mathrm{S}_{1}\right.$ to $\left.S_{6}\right)$ perpendicular to [100]: the three slabs, $S_{3}\left(S_{6}\right), S_{4}\left(S_{1}\right)$ and $\mathrm{S}_{5}\left(\mathrm{~S}_{2}\right)$ as shown in Figure 1a, are connected each other by sharing $\mathrm{O}_{4}$ and $\mathrm{O}_{5}$ to form the two sets of successive three slabs, $\mathrm{S}_{3}-\mathrm{S}_{4}-\mathrm{S}_{5}$, and $\mathrm{S}_{6}-\mathrm{S}_{1}-\mathrm{S}_{2}$. The $\mathrm{D}$ (or $\mathrm{D}^{\prime}$ in another orientation) type distortion of the six-membered rings occurs in each set of these successive slabs. On the other hand, the $\mathrm{O}$ (or $\mathrm{O}^{\prime}$ ) type rings occur only at the interfaces, where the two sets of slabs, $\mathrm{S}_{3}{ }^{-} \mathrm{S}_{4}{ }^{-} \mathrm{S}_{5}$ and $\mathrm{S}_{6}{ }^{-}$ $\mathrm{S}_{1}-\mathrm{S}_{2}$, share $\mathrm{O}_{6}$ atoms.

In a recent paper (Hirose et al., 2005), we reported the results of X-ray diffraction, DTA and Raman studies suggesting for MC to transform directly to OP between 110 and $115^{\circ} \mathrm{C}$. In the Raman measurements, 10 peaks appear in the range from 100 to $1250 \mathrm{~cm}^{-1}$ : peaks below $100 \mathrm{~cm}^{-1}$ were not observable in the experimental condition employed. The basic features in the observed Raman spectra are kept unchanged for the different phases of tridymite: at room temperature, six relatively sharp peaks appear between 200 and $500 \mathrm{~cm}^{-1}$, two around $800 \mathrm{~cm}^{-1}$, one around $1100 \mathrm{~cm}^{-1}$ and one around $1220 \mathrm{~cm}^{-1}$. The structural parameters in $\mathrm{MC}$ and $\mathrm{OP}$ were also refined at four temperatures, $25,80,90$ and $100^{\circ} \mathrm{C}$ for $\mathrm{MC}$, and at $140^{\circ} \mathrm{C}$ for OP. In that study, much attention was focused on the MSDs of atoms determined for the ordered structure models (i.e., each atom occupies the site corresponding to the single-minimum of potential energy), of MC and OP. The results lead us to conclude that the MC structure is ordered through its field up to the $\mathrm{MC}-\mathrm{OP}$ transition point. However, the MSDs of atoms in OP are too large to ascribe to the phonon modes only. The MSDs of $\mathrm{O}_{1}, \mathrm{O}_{2}, \mathrm{O}_{3}, \mathrm{O}_{4}$ and $\mathrm{O}_{5}$ in $\mathrm{OP}$ are strongly anisotropic with large magnitudes in the longest principal axes of the thermal ellipsoids, ranging from 0.15 to $0.18 \AA^{2}$ around 0.165 $\AA^{2}$ i.e., about $0.4 \AA$ in the root mean square (RMS) amplitudes. This RMS value is nearly equal with the radii of the circles for the $\mathrm{O}$ atom disorder in $\beta$-cristobalite (Nieuwenkamp, 1937; Peacor, 1973) and in HP (Kihara et al., 1980): according to these authors, $\mathrm{O}$ atoms in these high temperature phases of silica are randomly or regularly located on the circumferences of the circles normal to the $\mathrm{Si}-\mathrm{Si}$ axes. All the characteristic features indicated of the MSDs of $\mathrm{O}$ atoms in OP are just those of the orientation-disorder of $\mathrm{SiO}_{4}$ units over multiple minima.

Our purposes in the present study are to assign the normal modes characterized by symmetry-adapted atomic polarization vectors and frequencies to the experimental Raman spectra for MC and OP, and to find the relation between the low-frequency phonon modes and the suggested disorder in OP with respect to the extremely large MSDs.

\section{CALCULATIONS}

The Raman spectral data used in the present study were measured in our previous study (Hirose et al., 2005) on a fragmental specimen of $\mathrm{MC}$ taken from the surfaces of fired silica brick. Both the MC and OP structures have 72 atoms in their primitive cells. The 213 species of the optic modes at the zone center $\Gamma$ are classified as

$$
\Gamma=106 A^{\prime}+107 A^{\prime \prime}
$$

for MC with point group $m\left(C_{S}\right)$, and

$$
\Gamma=54 A+53 B_{1}+53 B_{2}+53 B_{3}
$$

for OP with point group $222\left(D_{2}\right)$, all Raman active: $A, A^{\prime}$, $A^{\prime \prime}, B_{1}, B_{2}$ and $B_{3}$ are the labels of the irreducible representations of the corresponding symmetry modes. The higher symmetry phases such as OC or HP have the smaller numbers of normal modes with their own frequencies. On the other hand, the MC and OP structures are the superstructures derived from HP by small distortions, and hence, bands, which are single in HP, may split into two or more in MC and OP, keeping the basic types of atom displacement patterns, characterized with the sets of atom polarization vectors, unchanged. In our observed Raman scattering profiles, only 10 peaks are observed, proving that some numbers of bands with a similar type of atomic displacement patterns (but with slightly different frequencies) contribute to a single peak. The peaks are numbered as indicated in Figure 2, and those positions are represented with the frequencies read from the peak tops. Because the peaks are contributed by some numbers of modes, the frequency values assigned are only for the convenience of explanation.

Using a single valence force field, Echepare et al. (1974) successfully calculated the wave numbers of the optic phonons in $\alpha^{-}$and $\beta$-quartz in good agreements with the observations for both the phases: in that study, 11 parameters were taken at first, but 9 parameters were enough to fit the 25 experimental frequencies. In the present study, the wave numbers and atomic polarization vectors in the optic modes at $\Gamma$ in MC and OP tridymites were calculated basically with the valence force field of Echepare et al. (1974) with the aid of a computer program VIBRATZ (Dowty, 1987). With program VIBRATZ, we can also calculate Raman spectral intensities: in the present calculations, the specimen was assumed to be a composite of materials in random orientations, and the spherical part and anisotropy part of the polarizability were chosen to the default values of the program, i.e., 45 and 0.1 , respectively. In the final stage of the calculations, two 
Table 1. Crystal data of monoclinic tridymite MC and orthorhombic tridymite OP, and valence force field parameters used in calculations

\begin{tabular}{lll}
\hline $\begin{array}{l}\text { Crystal data and force field } \\
\text { parameters }\end{array}$ & $\mathrm{MC}\left(25^{\circ} \mathrm{C}\right)^{*}$ & $\mathrm{OP}\left(140^{\circ} \mathrm{C}\right)$ \\
\hline Space group & $\mathrm{Aa}$ & $P 2_{1} 2_{1} 2_{1}$ \\
$a(\AA)$ & $25.878(3)$ & $26.163(9)$ \\
$b(\AA)$ & $5.001(8)$ & $4.987(2)$ \\
$c(\AA)$ & $8.526(2)$ & $8.199(3)$ \\
$\beta\left({ }^{\circ}\right)$ & $117.69(1)$ & - \\
Cell contents & $48 \mathrm{SiO}_{2}$ & $24 \mathrm{SiO}_{2}$ \\
\hline
\end{tabular}

Bond stretching, bending and interactions

Unit: stretching vibrations forces $10^{5} \mathrm{dyne} / \mathrm{cm}$; torsional bending forces $10^{-11} \mathrm{erg}$; interaction terms $10^{-3}$ dyne

\begin{tabular}{lll}
\hline$K_{1}: \mathrm{Si}-\mathrm{O}$ & 5.943 & 6.043 \\
$K_{2}: \mathrm{O}-\mathrm{Si}, \mathrm{Si}-\mathrm{O}$ & 0.711 & 0.811 \\
$K_{3}: \mathrm{Si}-\mathrm{O}, \mathrm{O}-\mathrm{Si}$ & 0.843 & 1.043 \\
$K_{4}: \mathrm{O}-\mathrm{Si}, \mathrm{O}-\mathrm{Si}-\mathrm{O}$ & 0.0 & 0.0 \\
$K_{5}: \mathrm{Si}-\mathrm{O}, \mathrm{O}-\mathrm{Si}-\mathrm{O}$ & -0.263 & -0.323 \\
$K_{6}: \mathrm{Si}-\mathrm{O}, \mathrm{Si}-\mathrm{O}-\mathrm{Si}$ & 0.398 & 0.148 \\
$K_{7}: \mathrm{O}-\mathrm{Si}-\mathrm{O}$ & 0.729 & 0.729 \\
$K_{8}: \mathrm{O}-\mathrm{Si}-\mathrm{O}, \mathrm{O}-\mathrm{Si}-\mathrm{O}$ & 0.0 & 0.0 \\
$K_{9}: \mathrm{O}-\mathrm{Si}-\mathrm{O}, \mathrm{O}-\mathrm{Si}-\mathrm{O}$ & -0.167 & -0.167 \\
$K_{10}: \mathrm{Si}-\mathrm{O}-\mathrm{Si}$ & 0.126 & 0.076 \\
$K_{11}: t(\mathrm{Si}-\mathrm{O})$ & $0.0(0.0056)$ & 0.0 \\
\hline
\end{tabular}

* Force field parameters are from Etchepare et al. (1974), except for $K_{11}$, which is shown in parentheses, but set to zero in the calculations.

valence force fields with parameters modified to improve the agreement for the intensity distribution were applied to the structural parameters of $\mathrm{MC}$ and $\mathrm{OP}$ determined for the ordered models in Hirose et al. (2005). The force parameters used are tabulated in Table 1, together with the crystal data. As seen in Table 1, a torsional parameter $t(\mathrm{Si}-\mathrm{O})$ was set null: including of this parameter causes for a weak intensity mode to appear at an unexpectedly high wave number.

\section{RESULTS}

\section{Calculated Raman spectra}

Figure $2(\mathrm{a}$ and $\mathrm{b}$ ) shows the calculated and experimental Raman spectra, respectively, for $\mathrm{MC}$ at $25^{\circ} \mathrm{C}$ : the calculated spectra are drawn assuming the line profile of the Gaussian function with the half- width of $10 \mathrm{~cm}^{-1}$ for each calculated band. The calculated and experimental Raman spectra for $\mathrm{OP}$ at $140^{\circ} \mathrm{C}$ are exhibited in Figure 2 (c and d), respectively: the calculated profile is drawn with the half width of $13 \mathrm{~cm}^{-1}$. The fits of the calculated peaks to the experimental are satisfactorily well for both $\mathrm{MC}$ and $\mathrm{OP}$ except for the slight departures of calculated peaks \#7 and
\#8 toward the lower wave-number sides. The experimental peaks \#7 and \#8 are closely located in the range from 750 to $790 \mathrm{~cm}^{-1}$, separated clearly in MC but barely in OP, whereas the calculated ones appear as a single broad peak at around $770 \mathrm{~cm}^{-1}$ for both the phases. It is noted that the changes of the force field parameters took effect in changing the frequencies of modes, but no notable effect in the atomic displacements.

The calculations on the ordered model for OC resulted in less satisfactory agreements with the experiments than for MC and OP as shown in Figure 2 (e and f). The calculated spectra with the same force field as in MC gave an extremely strong peak at about $100 \mathrm{~cm}^{-1}$, contrasting with the only weak peaks in those regions for OP and MC (Fig. 2e for the OC case with the half width of 15 $\mathrm{cm}^{-1}$ ). The averaged atomic distance $\mathrm{Si}^{-} \mathrm{O}$ and angle $\mathrm{Si}^{-} \mathrm{O}-\mathrm{Si}$ in the refinements of the ordered model of OC, $1.551 \AA$ and $173.5^{\circ}$, respectively, at $380^{\circ} \mathrm{C}$ (Kihara et al., 1986) seem abnormally low and large. We need to improve the structural model for OC to account for the spectroscopic data, but it is out of scope in the present study.

\section{Atomic displacements and bond-deformation patterns}

The silica frameworks in MC and OP are deformed from that in HP, resulting into the superstructure unit-cells. Correspondingly, the atom displacement or bond deformation patterns in a mode show some variations in the unit-cell. In this part of the result section, we characterize the atomic displacements (from the equilibrium positions) or those patterns and bond deformations on the basis of the calculated atomic polarization vectors (actual motions) in the normal modes for OP and MC.

Table 2 tabulates the wave numbers of the modes contributing to the 10 peaks between 100 and $1250 \mathrm{~cm}^{-1}$, in the cases of 25 and $140^{\circ} \mathrm{C}$, and also atoms showing predominant displacements in those modes. The $\mathrm{O}$ atom displacements are expressed on three orthogonal coordinates $p, q$ and $r$ defined in relation to $\mathrm{Si}^{-} \mathrm{O}^{-} \mathrm{Si}$ bonds: $p$ is parallel with the $\mathrm{Si}-\mathrm{Si}$ axis, $q$ in the $\mathrm{Si}^{-} \mathrm{O}-\mathrm{Si}$ plane and perpendicular to $p$, and $r$ completes the right-handed system, as illustrated in Figure 3. This coordinate system is convenient for expressing the displacements of $\mathrm{O}$ atoms in $\mathrm{Si}-\mathrm{O}-\mathrm{Si}$ bonds undergoing librational motions around the $\mathrm{Si}-\mathrm{Si}$ axes in the low frequency modes, and also for the $p$-type motions of $\mathrm{O}$ atoms in the high-frequency modes. The displacements of $q$-components are distinguished with their signs: unless the $\mathrm{Si}^{-} \mathrm{O}-\mathrm{Si}$ bonds move rigidly, large $q$ may represent bending the bonds, but $-q$ widening. We found that, in a mode, some $\mathrm{O}$ atoms displace in the $q$-directions, while other $\mathrm{O}$ atoms in $-q$. Most 


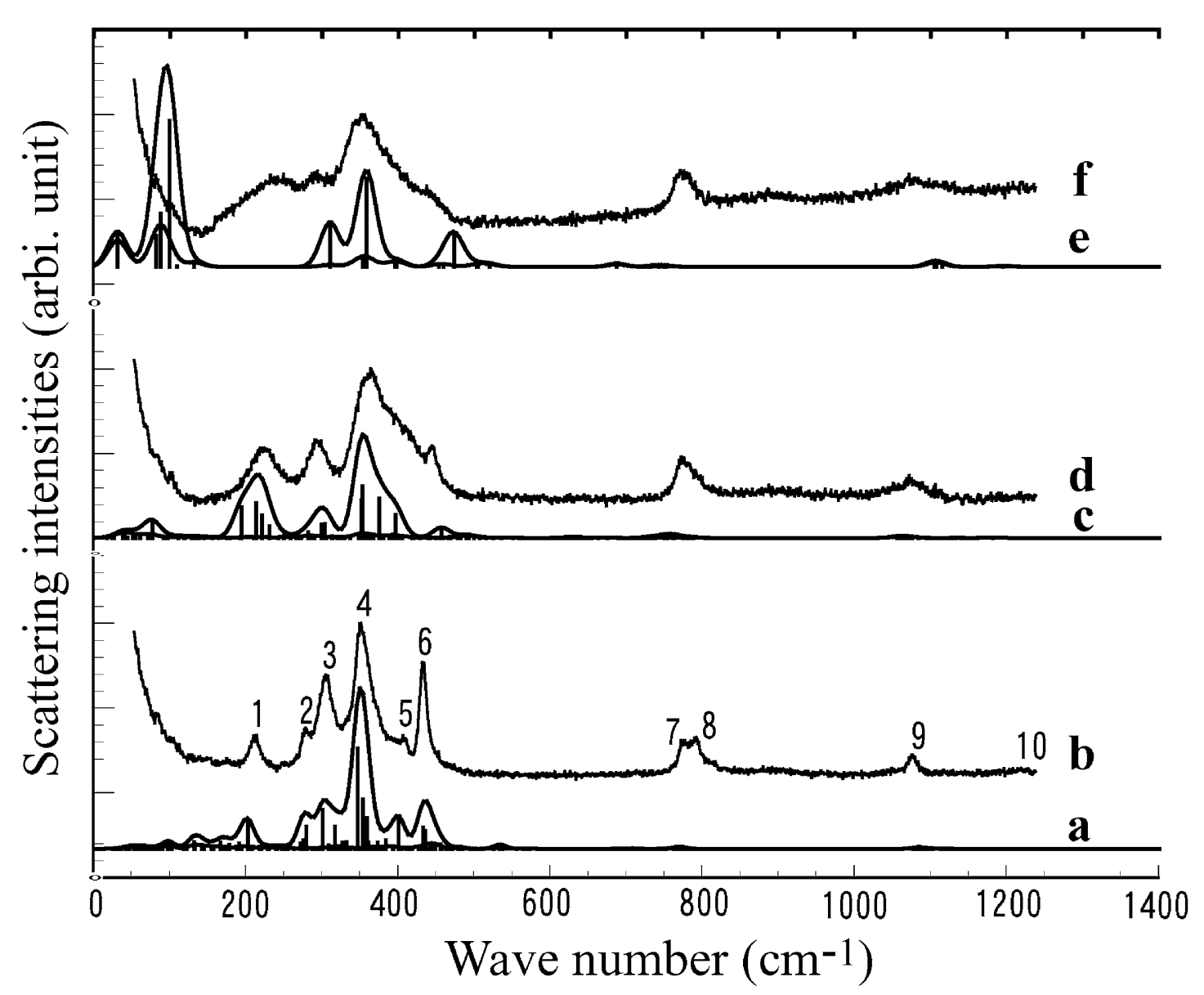

Figure 2. Calculated and experimental Raman spectra of monoclinic (MC) and two orthorhombic tridymites (OP and $\mathrm{OC}$ ), a and $\mathbf{c}$ for MC at $25^{\circ} \mathrm{C}$, $\mathbf{c}$ and $\mathbf{d}$ for $\mathrm{OP}$ at 140 and $\mathbf{e}$ and $\mathbf{f}$ for $\mathrm{OC}$ at $220^{\circ} \mathrm{C}$, respectively.

of the polarization vectors of $\mathrm{O}$ atoms in each mode involve non-zero three components. Then, in Table 2, the major components of atom displacements are indicated in parentheses in the decreasing orders from the largest. If the $\mathrm{Si}^{-} \mathrm{O}^{-} \mathrm{Si}$ angle is close to $180^{\circ}$, as observed for the apical $\mathrm{O}$ atoms in OP, components $q$ and $r$ become undistinguishable: such cases are noted with letter $q$ in Table 2. On the other hand, the displacements of Si atoms are significant in the bending (mainly in the low frequency modes above $200 \mathrm{~cm}^{-1}$ ) or stretching (in the high frequency modes below $1000 \mathrm{~cm}^{-1}$ ) of $\mathrm{Si}^{-} \mathrm{O}^{-} \mathrm{Si}$ bonds. Such $\mathrm{Si}$ displacements are more conveniently represented in relation with the deformations of $\mathrm{Si}^{-} \mathrm{O}-\mathrm{Si}$ bonds rather than in the individual displacements of the atoms. In the present study, thus, no attempt was made to characterize the polarization vectors of Si atoms on any internal coordinate system, specifically defined for the atoms.

The identification of the bond deformation types in the silica structures is not straightforward such as in simple molecules. In the framework structures of cornerlinked $\mathrm{SiO}_{4}$ tetrahedra, the distortions of $\mathrm{Si}^{-} \mathrm{O}-\mathrm{Si}$ or $\mathrm{SiO}_{4}$ are not separable each other. However, in the present cases, some parts of the frameworks show the characteristic features of deformations, letting us to extract 10 types to represent the deformation patterns in the concerned modes, of which seven are for $\mathrm{Si}^{-} \mathrm{O}^{-} \mathrm{Si}$ and three for $\mathrm{SiO}_{4}$. The former seven are denoted with symbols $v_{1}$ to $v_{7}$, and the latter three $v_{8}$ to $v_{10}$, as illustrated in Figure 4 . The bond deformations show variation from mode to mode, and even from bond to bond in modes. In a mode, some $\mathrm{Si}^{-} \mathrm{O}-\mathrm{Si}$ deform in just a type illustrated, but others in patterns not just fitting with those, or some of the types appear together, or a type (for example, bond stretching) and its reverse (compression with negative signs) appear together.

The deformations in the highest wave-number group of modes between 1150 and $1250 \mathrm{~cm}^{-1}$, contributing to peak \#10, are well represented with those of $\mathrm{SiO}_{4}$ tetrahedra in types $v_{8}, v_{9}$ and $v_{10}$, in which all the central $\mathrm{Si}$ atoms are nearly at rest. In $v_{10}$ (or $-v_{10}$ ), four $\mathrm{O}$ atoms in a $\mathrm{SiO}_{4}$ unit move about symmetrically toward (or away from) the central $\mathrm{Si}$ atom in the $p$-directions, whereas, in 
Table 2. Normal modes predominantly contributing to experimental Raman bands and major atom displacements in those modes for monoclinic tridymite MC, and orthorhombic tridymite OP

\begin{tabular}{|c|c|c|}
\hline \multirow{2}{*}{$\begin{array}{l}\text { Observed } \\
\text { peaks }{ }^{*} \text { at } 25 \\
\text { and } 140^{\circ} \mathrm{C} \\
\left(\mathrm{cm}^{-1}\right)\end{array}$} & \multicolumn{2}{|c|}{ Calculated major contributing modes } \\
\hline & OP & $\mathrm{MC}$ \\
\hline $\begin{array}{l}\# 1 \\
\text { MC: } 212 \\
\text { OP: } 224\end{array}$ & $\begin{array}{r}211.8 \mathrm{~cm}^{-1}: \mathrm{O}_{5}(r, q), \mathrm{O}_{6}(r, q), \mathrm{O}_{8}(q) \\
\mathrm{O}_{9}(r, q), \mathrm{O}_{10}(r, q), \mathrm{O}_{11}(q, r), \mathrm{O}_{12}(q) \\
192.6 \mathrm{~cm}^{-1}: \mathrm{O}_{5}(q), \mathrm{O}_{6}(q), \mathrm{O}_{7}, \mathrm{O}_{8}(q, r) \\
\mathrm{O}_{11}(r,-q), \mathrm{O}_{12}(q, r) \\
\end{array}$ & $\begin{array}{l}200.6 \mathrm{~cm}^{-1}: \mathrm{O}_{5}(r), \mathrm{O}_{14}(q, r), \mathrm{O}_{16}(r), \mathrm{O}_{17}(q, r), \mathrm{O}_{20}(r) \\
\quad \mathrm{O}_{21}(r, q), \mathrm{O}_{22}(r, q)\end{array}$ \\
\hline $\begin{array}{l}\# 2 \\
\text { MC: } 280 \\
\text { OP: } 295\end{array}$ & $\begin{array}{l}280.2 \mathrm{~cm}^{-1}: \mathrm{O}_{1 \mathrm{a}}(q), \mathrm{O}_{2 \mathrm{a}}(q), \mathrm{O}_{4}(r), \\
\mathrm{O}_{6}(r), \mathrm{O}_{7}(r), \mathrm{O}_{8}(r), \mathrm{O}_{10}(r, q), \mathrm{Si}_{2} \\
\mathrm{Si}_{5}, \mathrm{Si}_{6}\end{array}$ & $\begin{array}{l}278.0 \mathrm{~cm}^{-1}: \mathrm{O}_{10 \mathrm{a}}(q, r), \mathrm{O}_{11 \mathrm{a}}(q), \mathrm{O}_{12 \mathrm{a}}(r), \mathrm{O}_{22 \mathrm{a}}(q, r), \mathrm{O}_{23 \mathrm{a}}(q, r), \\
\quad \mathrm{O}_{24 \mathrm{a}}(q), \mathrm{O}_{5}(q, p), \mathrm{O}_{6}(-q), \mathrm{O}_{9}(r) .\end{array}$ \\
\hline $\begin{array}{l}\# 3 \\
\text { MC:306 }\end{array}$ & $\begin{array}{l}297.4 \mathrm{~cm}^{-1}: \mathrm{O}_{2 \mathrm{a}}(q), \mathrm{O}_{3 \mathrm{a}}(q), \mathrm{O}_{1 \mathrm{a}}(q) \\
\mathrm{O}_{7}(r), \mathrm{O}_{9}(r), \mathrm{O}_{11}(r), \mathrm{O}_{12}(q, r) \\
302.0 \mathrm{~cm}^{-1}: \mathrm{O}_{1 \mathrm{a}}(q), \mathrm{O}_{2 \mathrm{a}}(q), \mathrm{O}_{3 \mathrm{a}}(q) \\
\mathrm{O}_{6}(q), \mathrm{O}_{7}(r), \mathrm{O}_{8}(q), \mathrm{O}_{10}(r, q, p) \\
\mathrm{O}_{11}(r)\end{array}$ & $\begin{array}{c}299.2 \mathrm{~cm}^{-1}: \mathrm{O}_{1}(-q), \mathrm{O}_{5}(-q, r), \mathrm{O}_{6}(r,-q), \mathrm{O}_{8}(q), \mathrm{O}_{9}(-q), \\
\mathrm{O}_{10 \mathrm{a}}(-q, r), \mathrm{O}_{11 \mathrm{a}}(-q, r), \mathrm{O}_{12 \mathrm{a}}(-q, p), \mathrm{O}_{14}(-q), \mathrm{O}_{15}(q, r), \\
\mathrm{O}_{16}(r,-q), \mathrm{O}_{17}(r,-q), \mathrm{O}_{18}(r, q), \mathrm{O}_{20}(-q), \mathrm{O}_{23 \mathrm{a}}(r) \\
314.9 \mathrm{~cm}^{-1}: \mathrm{O}_{2}(r), \mathrm{O}_{4}(r,-q), \mathrm{O}_{5}(r,-q), \mathrm{O}_{6}(r,-q), \mathrm{O}_{7}(-q, r), \\
\mathrm{O}_{9}(r), \mathrm{O}_{10 \mathrm{a}}(r), \mathrm{O}_{11 \mathrm{a}}(r), \mathrm{O}_{17}(r), \mathrm{O}_{18}(-q, r), \mathrm{O}_{21}(-q, r, p), \\
\mathrm{O}_{22}(-q, r), \mathrm{O}_{24}(q)\end{array}$ \\
\hline $\begin{array}{l}\# 4 \\
\text { MC: } 353 \\
\text { OP: } 362\end{array}$ & $\begin{array}{c}350.1 \mathrm{~cm}^{-1}: \mathrm{O}_{2}(q), \mathrm{O}_{4}(-q, p), \mathrm{O}_{5}(r) \\
\mathrm{O}_{6}(q), \mathrm{O}_{7}(-q, r), \mathrm{O}_{9}(r, q), \mathrm{O}_{10}(r, p) \\
\mathrm{O}_{11}(r,-q), \mathrm{O}_{12}(-q), \mathrm{Si}_{1}, \mathrm{Si}_{2}, \mathrm{Si}_{3}, \mathrm{Si}_{6} \\
351.6 \mathrm{~cm}^{-1}: \mathrm{O}_{4}(-q, p), \mathrm{O}_{5}(r,-q), \mathrm{O}_{6}(q) \\
\mathrm{O}_{7}(r,-q), \mathrm{O}_{10}(-q), \mathrm{O}_{11}(r,-q) \\
373.6 \mathrm{~cm}^{-1}: \mathrm{O}_{1 \mathrm{a}}(q), \mathrm{O}_{8}(q, r), \mathrm{O}_{9}(q, r) \\
\mathrm{O}_{10}(r)\end{array}$ & $\begin{array}{l}345.5 \mathrm{~cm}^{-1}: \mathrm{O}_{1}(-q, r), \mathrm{O}_{2}(-q, r), \mathrm{O}_{4}(-q), \mathrm{O}_{5}(r), \mathrm{O}_{6}(r,-q), \\
\quad \mathrm{O}_{7}(r), \mathrm{O}_{9}(-q), \mathrm{O}_{10}(r,-q), \mathrm{O}_{11}(r,-q), \mathrm{O}_{12}(r,-q), \mathrm{O}_{13}(r,-q), \\
\mathrm{O}_{22}(-q, r), \mathrm{O}_{23}(-q, \mathrm{r}) . \\
352.4 \mathrm{~cm}^{-1}: \mathrm{O}_{6}(q, r), \mathrm{O}_{10 \mathrm{a}}(-q), \mathrm{O}_{13}(q), \mathrm{O}_{14}(q, r), \mathrm{O}_{17}(r), \\
\quad \mathrm{O}_{18}(q, r) \\
357.7 \mathrm{~cm}^{-1}: \mathrm{O}_{7}(q, r), \mathrm{O}_{11 \mathrm{a}}(q, r), \mathrm{O}_{12 \mathrm{a}}(q, r), \mathrm{O}_{14}(r,-q), \mathrm{O}_{17}(r), \\
\mathrm{O}_{24 \mathrm{a}}(q)\end{array}$ \\
\hline MC: 408 & $\begin{array}{c}395.2 \mathrm{~cm}^{-1}: \mathrm{O}_{2 \mathrm{a}}(q), \mathrm{O}_{3 \mathrm{a}}(q), \mathrm{O}_{4}(q) \\
\mathrm{O}_{5}(q), \mathrm{O}_{8}(-q), \mathrm{O}_{9}(-q, r), \mathrm{O}_{10}(-q) \\
\mathrm{O}_{11}(r), \mathrm{O}_{12}(-q)\end{array}$ & $\begin{array}{l}398.8 \mathrm{~cm}^{-1}: \mathrm{O}_{6}(q, r), \mathrm{O}_{8}(q), \mathrm{O}_{9}(-q), \mathrm{O}_{11 \mathrm{a}}(r), \mathrm{O}_{12 \mathrm{a}}(q), \mathrm{O}_{17}(q), \\
\mathrm{O}_{18}(-q, r), \mathrm{O}_{21}(q), \mathrm{O}_{23 \mathrm{a}}(q, r)\end{array}$ \\
\hline $\begin{array}{l}\# 6 \\
\text { MC:433 } \\
\text { OP: } 444\end{array}$ & $\begin{array}{c}455.3 \mathrm{~cm}^{-1}: \mathrm{O}_{4}(q), \mathrm{O}_{5}(-q), \mathrm{O}_{6}(-q) \\
\mathrm{O}_{9}(-q), \mathrm{O}_{10}(r), \mathrm{Si}_{1}, \mathrm{Si}_{3}, \mathrm{Si}_{5}\end{array}$ & $\begin{array}{l}431.2 \mathrm{~cm}^{-1}: \mathrm{O}_{8}(r, q), \mathrm{O}_{10 \mathrm{a}}(r), \mathrm{O}_{11 \mathrm{a}}(r), \mathrm{O}_{12}(-q, r), \mathrm{O}_{17}(q, r), \\
\mathrm{O}_{22 \mathrm{a}}(q), \mathrm{O}_{23 \mathrm{a}}(q), \mathrm{O}_{24 \mathrm{a}}(q) . \\
433.3 \mathrm{~cm}^{-1}: \mathrm{O}_{12}(-q, r), \mathrm{O}_{14}(-q, r), \mathrm{O}_{16}(r), \mathrm{O}_{19}(r), \mathrm{O}_{20}(q), \mathrm{Si}_{9}, \\
\mathrm{Si}_{10}, \mathrm{Si}_{11}\end{array}$ \\
\hline $\begin{array}{l}\# 7 \\
\text { MC: } 776 \\
\text { OP: } 775\end{array}$ & $\begin{array}{l}752.7 \mathrm{~cm}^{-1}: \mathrm{Si}_{1}, \mathrm{Si}_{2}, \mathrm{Si}_{3}, \mathrm{Si}_{4}, \mathrm{Si}_{5}, \mathrm{O}_{5}(q) \\
761.7 \mathrm{~cm}^{-1}: \mathrm{Si}_{1}, \mathrm{Si}_{2}, \mathrm{Si}_{3}, \mathrm{Si}_{4}, \mathrm{Si}_{5}, \mathrm{Si}_{6}\end{array}$ & $\begin{array}{l}763.3 \mathrm{~cm}^{-1}(A "): \mathrm{Si}_{7}, \mathrm{Si}_{8}, \mathrm{O}_{15}(-q), \mathrm{O}_{14}(-q) \\
766.2 \mathrm{~cm}^{-1}: \text { All Si } \\
769.1 \mathrm{~cm}^{-1}: \text { All Si. } \mathrm{O}_{3}(q) .\end{array}$ \\
\hline $\begin{array}{l}\# 8 \\
\text { MC:791 }\end{array}$ & $786.5 \mathrm{~cm}^{-1}: \mathrm{Si}_{2}, \mathrm{Si}_{6}, \mathrm{O}_{8}(-q), \mathrm{O}_{10}(q)$ & $\begin{array}{l}773.8 \mathrm{~cm}^{-1}: \mathrm{Si}_{10}, \mathrm{Si}_{11}, \mathrm{Si}_{12}, \mathrm{O}_{20}(-q) \\
778.3 \mathrm{~cm}^{-1}: \mathrm{Si}_{3}, \mathrm{Si}_{4}, \mathrm{O}_{5}(-q), \mathrm{O}_{6}(q)\end{array}$ \\
\hline $\begin{array}{l}\# 9^{* *} \\
\text { MC: } 1078 \\
\text { OP: } 1074\end{array}$ & $\begin{array}{l}1056 \mathrm{~cm}^{-1}: \mathrm{O}_{7}, \mathrm{O}_{9}, \mathrm{Si}_{1}, \mathrm{Si}_{5} \\
1057.5 \mathrm{~cm}^{-1}\left(B_{1}\right): \mathrm{O}_{5}, \mathrm{O}_{10} \\
1070.9 \mathrm{~cm}^{-1}\left(B_{1}\right): \mathrm{O}_{4}, \mathrm{O}_{11} \\
1055.6 \mathrm{~cm}^{-1}\left(B_{2}\right): \mathrm{O}_{7}, \mathrm{O}_{9}, \mathrm{Si}_{1}, \mathrm{Si}_{5}\end{array}$ & $\begin{array}{l}1075.3 \mathrm{~cm}^{-1}: \mathrm{O}_{5}, \mathrm{O}_{6}, \mathrm{Si}_{3}, \mathrm{Si}_{4} \\
1079.1 \mathrm{~cm}^{-1}: \mathrm{O}_{8}, \mathrm{O}_{9}, \mathrm{Si}_{5}, \mathrm{Si}_{6} \\
1081.5 \mathrm{~cm}^{-1}: \mathrm{O}_{19}, \mathrm{O}_{20}, \mathrm{O}_{21} \\
1083.3 \mathrm{~cm}^{-1}: \mathrm{O}_{2}, \mathrm{O}_{3}, \mathrm{Si}_{1}, \mathrm{Si}_{2} \\
1084.8 \mathrm{~cm}^{-1}: \mathrm{O}_{14}, \mathrm{O}_{15}, \mathrm{Si}_{7}, \mathrm{Si}_{8} \\
1089.7 \mathrm{~cm}^{-1}: \mathrm{O}_{11}, \mathrm{O}_{17}, \mathrm{O}_{18}, \mathrm{O}_{19}, \mathrm{O}_{23}\end{array}$ \\
\hline $\begin{array}{l}\# 10^{* * *} \\
\text { MC: } 1220 \\
\text { OP: } 1210\end{array}$ & $\begin{array}{l}1180.8 \mathrm{~cm}^{-1}\left(B_{3}\right) \\
1205 \mathrm{~cm}^{-1}\left(B_{2}\right) \\
1223.5 \mathrm{~cm}^{-1}\left(B_{3}\right) \\
1226.3 \mathrm{~cm}^{-1} \\
1232.7 \mathrm{~cm}^{-1}\left(B_{1}\right)\end{array}$ & $\begin{array}{l}1176.0 \mathrm{~cm}^{-1} \\
1185.1 \mathrm{~cm}^{-1}\left(A^{\prime \prime}\right) \\
1195.8 \mathrm{~cm}^{-1}\left(A^{\prime \prime}\right) \\
1198.5 \mathrm{~cm}^{-1}\end{array}$ \\
\hline
\end{tabular}

$\mathrm{O}$ atom displacements are expressed on coordinates $p, q$ and $r$.

For MC and OP, modes belong to irreducible representations $A^{\prime}$ and $A$, respectively, unless indicated.

* Top positions are read after smoothing.

** $\mathrm{O}$ displacements are all in the $p$-type in $\mathrm{MC}$ and $\mathrm{OP}$.

*** Only $\mathrm{O}$ atoms show significant displacements in the $p$-type in $\mathrm{MC}$ and $\mathrm{OP}$. 


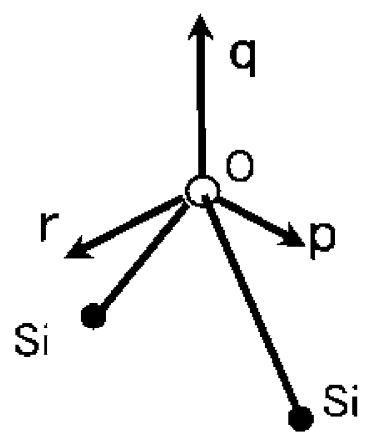

Figure 3. Internal coordinates for $\mathrm{O}$ atom displacements in $\mathrm{Si}^{-} \mathrm{O}$ $\mathrm{Si}$.

$v_{9}\left(\right.$ or $\left.-v_{9}\right)$ and $v_{8}\left(\right.$ or $\left.-v_{8}\right)$ only three and two $\mathrm{O}$ atoms respectively move toward (or away from) the remaining $\mathrm{O}$ atom(s), respectively, which is (are) nearly at rest.

The deformations in the modes between 1000 and $1150 \mathrm{~cm}^{-1}$, contributing to peak $\# 9$, are represented with those of $\mathrm{Si}^{-} \mathrm{O}^{-} \mathrm{Si}$ in $v_{6}$ and $v_{7}$, and may be compared with the antisymmetric stretching patterns in three-atom molecules such as $\mathrm{H}_{2} \mathrm{O}$ etc. (The words symmetric or antisymmetric are used in a loose sense here with respect to the distortions of the $\mathrm{SiO}_{4}$ unit or $\mathrm{Si}^{-} \mathrm{O}-\mathrm{Si}$ bond concerned, respectively: these can be seen having the tetrahedral or two-fold symmetry around $q$ or the mirror planes perpendicular to $p$ only in rough approximation.)

The bond deformations in the modes contributing to peaks \#7 and \#8 are represented with those of $\mathrm{Si}-\mathrm{O}-\mathrm{Si}$, but show more variation than in modes for peak \#9. Most deformation patterns in this group of deformations are identified or related to the five types from $v_{1}$ to $v_{5}$ (Fig. 4): types $v_{1}$ and $v_{2}$ occur in either the linear or bent (viewed along $p$ ) $\mathrm{Si}^{-} \mathrm{O}-\mathrm{Si}$, and types $v_{3}, v_{4}$ and $v_{5}$ in the bent bonds. In some cases, $\mathrm{Si}$ displacements are significantly out of the planes of drawing in Figure $4\left(20\right.$ to $\left.30^{\circ}\right)$ toward the different sides each other. In such deformations, the two $\mathrm{Si}$ atoms move to the transpositions for the central $\mathrm{O}$ atoms, and then those are denoted with subscript $T$ such as $v_{3 T}$.

The major $\mathrm{Si}^{-} \mathrm{O}-\mathrm{Si}$ deformation types are listed in Table 3 for the major modes contributing to peaks \#7, \#8 and \#9 (letter $L$ is used to distinguish the bonds angles larger than $175^{\circ}$ ).

\section{Assignment of Raman spectra and detailed descrip- tion of atomic displacement patterns}

In (a) of this part, the calculated normal modes are assigned to the experimental Raman peaks, and the atomic polarization vectors and bond deformations, if any, related to such modes are given on the basis of internal coordinate systems defined above. The present calculations show that $23\left(7 A+5 B_{1}+6 B_{2}+5 B_{3}\right)$ modes for OP and 22 $\left(10 A^{\prime}+12 A^{\prime \prime}\right)$ modes for MC are located below $100 \mathrm{~cm}^{-1}$. In the $B_{1}, B_{2}$ or $B_{3}$ mode, the polarization vectors of atoms are antisymmetric against a couple of $2_{1}$ in [100] and [010], [100] and [001] or [010] and [001], respectively. Although no data was available in our (previous) experiments, because the frequencies were too low to observe, these low-frequency modes were examined with special attention to find relations with the characteristic features in atomic MSDs in OP. The atomic displacements and bonddeformations in these low frequency groups of modes are reported in (b), especially for OP.

The modes with significant Raman intensities mostly belong to representation $A^{\prime}$ or $A$ for MC or OP, respectively, whereas, in OP, some $B_{1}, B_{2}$ and $B_{3}$ modes are significant in the high frequency range above $1000 \mathrm{~cm}^{-1}$. In the following descriptions, the normal modes belong to $A^{\prime}$ for MC and $A$ for OP, unless indicated. The dominantly contributing modes and the frequency (wave-number) values are tabulated in Table 2.

\section{(a) Major modes contributing to experimental Raman peaks from \#1 to \#10}

In this part, some details of the normal modes dominantly contributing to the experimental peaks are described for each peak. Some peaks are explained separately for OP and $\mathrm{MC}$, if the modes contributing to the peaks show differences to be noted for the two phases.

Peak \#1. In the modes contributing to this peak, the $\mathrm{O}$ atom motions with the large $r^{-}$(librational motions of $\mathrm{Si}^{-}$ $\mathrm{O}-\mathrm{Si}$ around $\mathrm{Si}-\mathrm{Si}$ ) or large $q$-components, or with both the components are remarkable with the small displacements of $\mathrm{Si}$.

OP. The major contribution is from four modes, which, particularly the 211.8 and $192.6 \mathrm{~cm}^{-1}$ modes, cause this peak to be broader and stronger in OP than in $\mathrm{MC}$. The $\mathrm{O}$ atoms show large displacements except for the apical $\mathrm{O}$ atoms. All the Si atoms show the nearly equal magnitudes of displacements, obviously a half to one third of those for $\mathrm{O}$ atoms.

MC. The major contribution is from the $200.6 \mathrm{~cm}^{-1}$ mode. No distinction is apparent between the apical and basal $\mathrm{O}$ atoms.

Peak \#2. In the modes contributing to this peak, the $\mathrm{O}$ atom motions with the large $q^{-}$or $r$-components (librational motions of $\mathrm{Si}^{-} \mathrm{O}^{-} \mathrm{Si}$ around $\mathrm{Si}^{-} \mathrm{Si}$ ) or with both the components are remarkable with the small displacements of $\mathrm{Si}$.

OP. The mode at $280.2 \mathrm{~cm}^{-1}$ appears to form a single peak together with peak \#3.

MC. The mode at $278.0 \mathrm{~cm}^{-1}$ stands to keep peak \#2 separated from others. 
Table 3. Major modes contributing to peaks \#7, \#8 and \#9, and major $\mathrm{Si}-\mathrm{O}-\mathrm{Si}$ deformation types in orthorhombic tridymite $\mathrm{OP}$ and monoclinic tridymite $\mathrm{MC}$

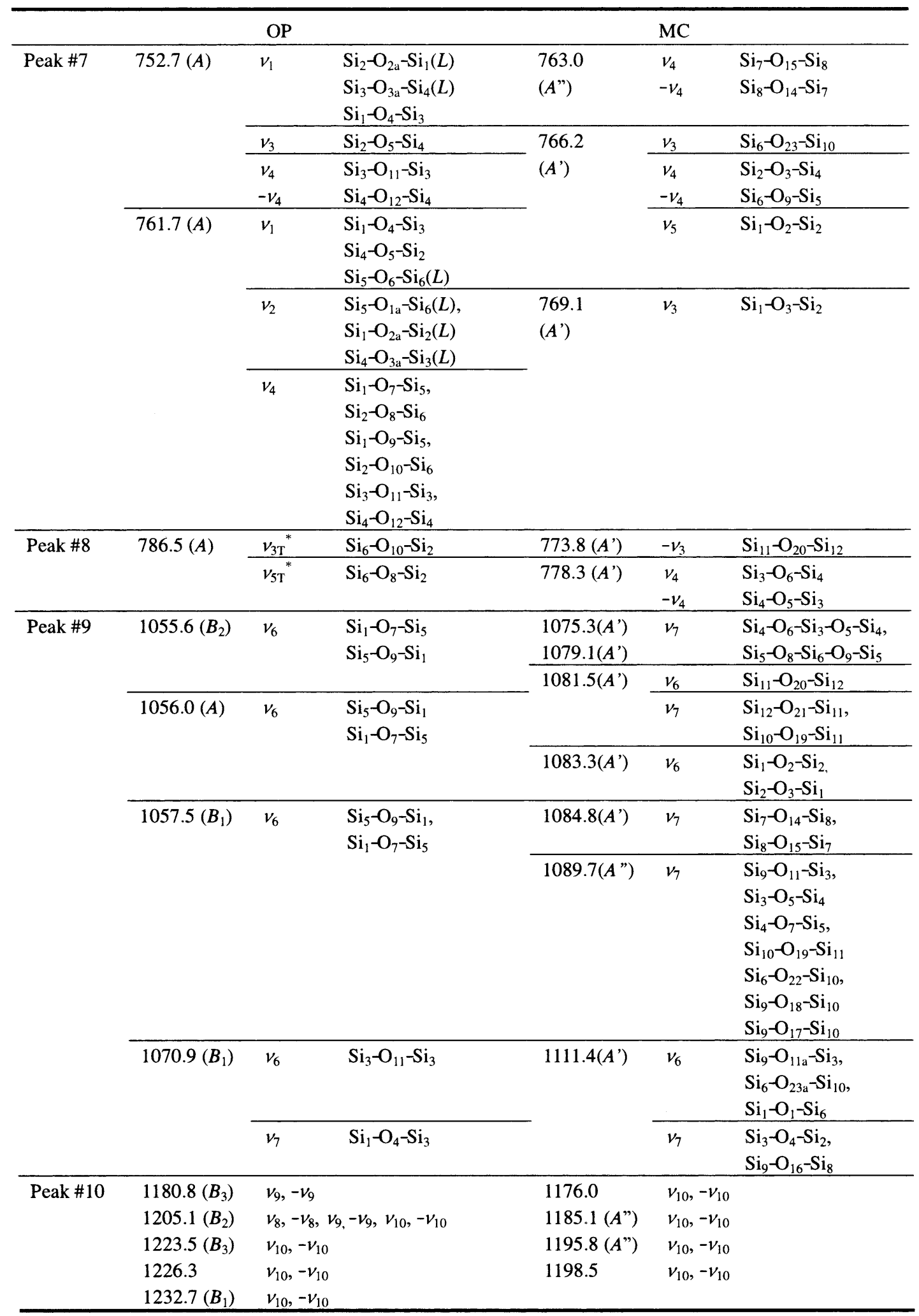

The letter $L$ indicates a bond angle larger than $175^{\circ}$.

Types with negative signs indicate that the corresponding bonds deform in the reverse directions to those illustrated in Figure 4.

${ }^{*} \mathrm{Si}$ atoms displace out of the bonding planes $\left(20\right.$ to $\left.30^{\circ}\right)$ toward different sides, i.e., transpositions, from each other. 

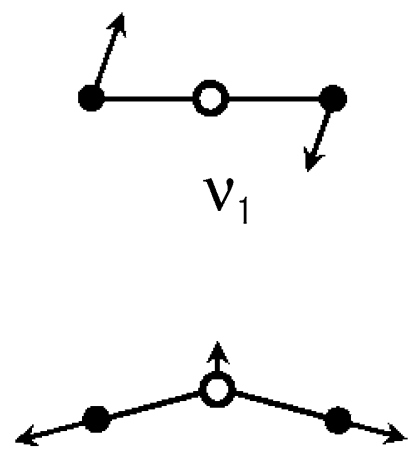

$v_{3}$

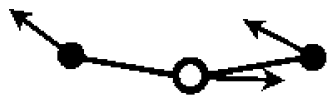

$v_{6}$

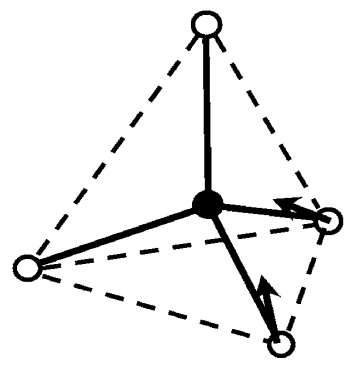

$v_{8}$
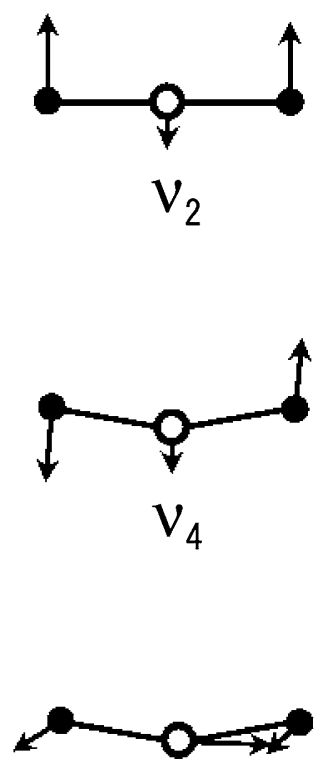

$v_{7}$

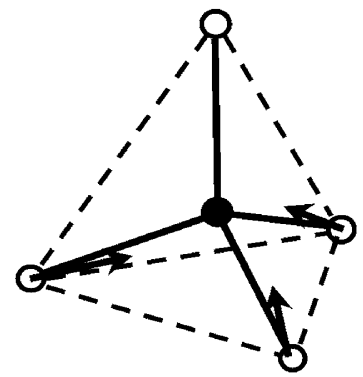

$v_{9}$

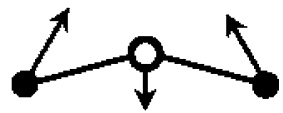

$v_{5}$

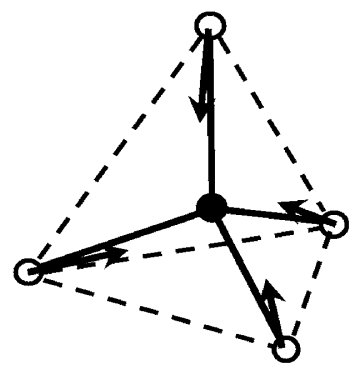

$v_{10}$

Figure 4. Typical types of bond deformations for $\mathrm{Si}^{-} \mathrm{O}-\mathrm{Si}$ and $\mathrm{SiO}_{4} . v_{1}$ to $v_{7}$ for $\mathrm{Si}^{-} \mathrm{O}^{-} \mathrm{Si}$, and $v_{8}$ to $v_{10}$ for $\mathrm{SiO}_{4}$. For $v_{1}$ and $v_{2}$, $\mathrm{Si}-\mathrm{O}_{-}-\mathrm{Si}$ is linear or bent, but viewed along its plane. For $v_{3}$ to $v_{7}, \mathrm{Si}-\mathrm{O}-\mathrm{Si}$ is viewed down perpendicular to its plane. Deformations $v_{1}$ to $v_{5}$ appear in modes of groups \#7 and \#8, $v_{6}$ and $v_{7}$ in group \#9, and $v_{8}$ to $v_{10}$ in group \#10.

Peak \#3. The major contribution is from two modes in both $\mathrm{MC}$ and OP. In the modes contributing to this peak, the $q^{-}$(or ${ }^{-q^{-}}$) or $r^{-}$or both components are remarkable for the $\mathrm{O}$ atoms. The $\mathrm{Si}$ atom displacements are relatively small, but notable. Some ...Si-O-Si-O-Si... chains appear to move as groups.

Peak \#4. The large $\mathrm{O}$ atom displacements in the $q^{-}$(or $q^{-}$) or $r^{-}$or both components are remarkable.

OP. The major contribution is from three modes. In the mode at $350.1 \mathrm{~cm}^{-1}$, in addition to the $\mathrm{O}$ atom displacements, the $\mathrm{Si}$ atom displacements are remarkable. This feature in the atom displacements is kept in other two modes at $351.6 \mathrm{~cm}^{-1}$ and $373.6 \mathrm{~cm}^{-1}$, except for the small $\mathrm{Si}$ atom displacements.

MC. The major contribution is from three modes, where the $\mathrm{Si}$ displacements are all negligible.
Peak \#5. The major contribution is from a mode in both $\mathrm{MC}$ and OP. The $\mathrm{O}$ atom displacements are remarkable and dominated by the $q^{-}$(or ${ }^{-} q^{-}$) or $r$-components. The $\mathrm{Si}$ atom displacements are small.

Peak \#6. The major contribution is from one or two modes in $\mathrm{OP}$ or $\mathrm{MC}$, respectively. The $\mathrm{Si}$ atom displacements increase with the large displacements of some $\mathrm{O}$ atoms in the $q^{-}$(or ${ }^{-} q^{-}$) or $r^{-}$or both components.

Peaks \#7 and \#8. In these groups, the $\mathrm{Si}$ atom displacements become significant both in OP and $\mathrm{MC}$, although the displacements of some $\mathrm{O}$ atoms become negligible. The deformations of $\mathrm{Si}-\mathrm{O}-\mathrm{Si}$ bonds in characteristic patterns $v_{1}$ to $v_{5}$ as illustrated in Figure 4 are prevalent in these modes. The $\mathrm{Si}^{-} \mathrm{O}-\mathrm{Si}$ deformation patterns in the major modes are collected in Table 3.

OP. The major contribution is from the three modes at 
752.7, 761.7 and $786.5 \mathrm{~cm}^{-1}$, of which the first two may be assigned to peak \#7 and the last to peak \#8. In these modes, deformations $v_{1}$ to $v_{4}$ occur to make deformation chains ...-Si-O-Si-O-Si-O-Si- ${ }^{-}$.. composed of the basal $\mathrm{O}$ atoms with the $\mathrm{Si}$ atoms in the nearly anti-parallel displacements, oblique to the $\mathrm{Si}-\mathrm{O}$ bonds.

MC. Deformations $v_{3}$ to $v_{5}$ occur. The major contribution is from the five modes at $763.3\left(\mathrm{~A}^{\prime \prime}\right), 766.2,769.1,773.8$ and $778.3 \mathrm{~cm}^{-1}$. The last two have the strongest intensities among these, and then the last one may be assigned to peak \#8 and the others to \#7. In these modes, Si atoms move toward the anti-bonding spaces. In the mode at $763.3\left(\mathrm{~A}^{\prime \prime}\right) \mathrm{cm}^{-1}$, the significant displacements of Si connect the deformations of two $\mathrm{Si}^{-} \mathrm{O}-\mathrm{Si}$ bonds in $v_{4}$ and in $-v_{4}$, respectively, to make the deformation chains of .......Si-O-O-Si-O-Oi-O....

Peak \#9. The calculated modes with the wave numbers between 1000 and $1150 \mathrm{~cm}^{-1}$ are assigned to this peak. The $p$-type displacements of $\mathrm{O}$ atoms become important in deforming the $\mathrm{Si}-\mathrm{O}-\mathrm{Si}$ bonds remarkably with the anti-symmetric bond stretching (or compression) components in types $v_{6}$ and $v_{7}$. The distortion types in the major modes contributing to this group are also shown in Table 3. In many cases, the distortions of $\mathrm{Si}^{-} \mathrm{O}-\mathrm{Si}$ are transferred to the next ones to make the deformation chains of the same types.

Peak \#10. The modes with strong calculated intensities between 1150 and $1250 \mathrm{~cm}^{-1}$ are assigned to this peak. In these high frequency modes, the Si displacements are mostly negligible, and the $\mathrm{O}$ atom displacements are in the $p$-type, resulting into the deformations of $\mathrm{SiO}_{4}$ in the compression (or stretching) of types $v_{8}\left(-v_{8}\right)$ to $v_{10}\left({ }^{-} v_{10}\right)$. The distortion types in the major modes contributing to this group are also shown in Table 3.

\section{(b) Modes with low frequencies}

Some low wave-number modes below $100 \mathrm{~cm}^{-1}$ are considered here focusing on OP.

$15.7 \mathbf{~ c m}^{-1}$ mode in A. This is the lowest frequency optic mode at $\Gamma$, where the typical $r$-component motions of $\mathrm{O}_{12}, \mathrm{O}_{8}$ and $\mathrm{O}_{10}$, and the motions of $\mathrm{Si}_{4}$ and $\mathrm{Si}_{6}$ are remarkable. These motions of atoms occur in groups: the displacement vectors are roughly directed oppositely along [010] and [010], whose directions change at $\mathrm{O}_{4}, \mathrm{O}_{5}$ and $\mathrm{O}_{6}$. This type of alternating change in groups reminds us the view based on the slabs perpendicular to [100] of the orthorhombic cell. Essentially the same type of displacement pattern is also seen in the next low frequency $A$ mode of $39.1 \mathrm{~cm}^{-1}$.

$22.8 \mathbf{~ c m}^{-1}$ mode in $B_{1}$. Slabs $S_{2}$ and $S_{3}$ move oppositely in [010] or [0 $\overline{10}$, and this type displacement pattern is repeated for the pair of the slabs $S_{5}$ and $S_{6}$ via $S_{4}$, where the atomic displacements are small and rather crossing with [010].

$18.1 \mathbf{~ c m}^{-1}$ mode in $B_{2}$. Not all the atoms, but only limited atoms, $\mathrm{O}_{12}$ and $\mathrm{Si}_{4}$, in both the slabs $\mathrm{S}_{1}$ and $\mathrm{S}_{3}$, show large displacements with the major components in [010] or [0̄ㅣㄹ.

$24.7 \mathbf{c m}^{-1}$ mode in $B_{3} . \mathrm{O}_{8}, \mathrm{O}_{10}, \mathrm{Si}_{2}$ and $\mathrm{Si}_{6}$, all in slabs $\mathrm{S}_{2}$ and $S_{3}$ (or $S_{5}$ and $S_{6}$ ), show large displacements toward around [010] or [010], respectively.

$74.9 \mathrm{~cm}^{-1}$ mode in $B_{3}$. The atom polarization vectors are illustrated in Figure 1a. All the apical $\mathrm{O}$ atoms and $\mathrm{O}_{4}, \mathrm{O}_{5}$ and $\mathrm{O}_{6}$ of the basal $\mathrm{O}$ atoms show remarkable displacements along the $q$-directions nearly parallel with [100], and the $r$-directions nearly in (010). These characteristic motions of the selected atoms just suggest for all the rigid $\mathrm{SiO}_{4}$ units to undergo librations around the axes passing the central $\mathrm{Si}$ atoms, whose directions are all nearly parallel with [010]. The displacement pattern of $\mathrm{O}$ atoms is in an excellent harmony with the directions and lengths of the principal axes of the thermal ellipsoids of $\mathrm{O}$ atoms.

The atomic displacements in the low frequency modes in MC lack such a strong tendency to undergo grouped motions as observed in OP, except the lowest frequency $A^{\prime}$ mode with $28 \mathrm{~cm}^{-1}$, in which atomic motions are grouped for the tridymite layers: one move toward about parallel with [100], while its neighbors go oppositely.

\section{DISCUSSION}

The calculated Raman spectra for the MC and OP structures using the valence force fields are satisfactory in reproducing the observed ones. In Etchepare et al. (1978), the authors concluded that their valence force field, successfully applied to quartz (Etchepare et al. 1974), is also applicable to low cristobalite. With the present results, we add that their valence force field is also applicable to MC tridymite, omitting torsional parameter $K_{11}$. The calculated Raman spectra for the ordered structure of OP need the adjustments of the most force parameters except the bending of the $\mathrm{O}^{-} \mathrm{Si}^{-} \mathrm{O}$ angle to fit with the experimental spectra. In spite of these different values applied to both the phases of tridymite, the calculated normal modes with frequencies and polarization vectors keep the essential features unchanged, and reasonably reflect the differences in their structural details. The calculated values for OP are also comparable with those for low quartz, as shown later. The present success of the ordered structure suggests for the disorder in the OP structure to be such that its effects in the calculations are apparently cancelled with the adjustments of the force parameters.

For both MC and OP, we divide the 213 optic spe- 
cies (without taking account of the TO-LO splitting) at the $\Gamma$-point into the 11 groups of modes, of which 10 correspond to the observed Raman peaks \#1 to \#10, and the remaining one to the low wave number modes below 100 $\mathrm{cm}^{-1}$. Each group of modes shows a characteristic atom displacement or bond-deformation pattern. Although both $\mathrm{MC}$ and OP share the essential features in their corresponding normal modes, the atom displacement patterns differ in details, particularly in the low-frequency modes at about $200 \mathrm{~cm}^{-1}$ or lower, reflecting the differences in the ways for the distorted six-membered rings in the $\mathrm{O}$ $\left(\mathrm{O}^{\prime}\right)$ or $\mathrm{D}\left(\mathrm{D}^{\prime}\right)$ types to stack along the pseudohexagonal $c^{-}$ axis. In the low-frequency modes in OP, the apical O atoms tend to show different behaviors from those for the basal $\mathrm{O}$ atoms, whereas, in MC, such a distinction is not obvious for $\mathrm{O}$ atoms. The atom displacements in some normal modes below $100 \mathrm{~cm}^{-1}$ in OP appear as groups in the forms of the slabs perpendicular to [100] of the orthorhombic superstructure-cell. The structural differences are also reflected in the modes of group \#10: the $v_{8}{ }^{-}$and $v_{9}$-type distortions are not found for $\mathrm{MC}$.

The normal modes in $\mathrm{MC}$ and $\mathrm{OP}$ tridymites are here compared with those in low quartz with point group 32: the (27-3) optic modes at the $\Gamma$-point are divided up into symmetry modes $4 A_{1}+4 A_{2}+8 E$. The normal modes belonging to groups \#10, \#9, \#8, \#7, \#6, \#4 and \#1 of the tridymites have their counterparts in low quartz: the frequencies and the polarization vectors in low quartz referred in the present study are calculated with the force field of Etchepare et al. (1974). In low quartz, the highest frequency band $(E)$ at $1153 \mathrm{~cm}^{-1}$ involves the $v_{10}$-type deformations of $\mathrm{SiO}_{4}$ units (with the small Si displacements), and the $1076 \mathrm{~cm}^{-1}$ mode (E) the $v_{7}$-type deformations of $\mathrm{Si}-\mathrm{O}-\mathrm{Si}$. The $v_{4}-$ and $v_{5}$-type deformations appear in the $792\left(A_{2}\right), 765(E)$ and $712(E) \mathrm{cm}^{-1}$ modes in low quartz. In the modes corresponding to group \#6 and lower, the $\mathrm{O}$ atom displacements in the $r$ - and $q$-types become dominant, similarly to for the tridymites. As exemplified here, the normal modes in quartz and the tridymites share the essential features in the atom displacements or bond deformations each other. Nevertheless, their details should be different because of the different topologies in the $\mathrm{SiO}_{4}$ frameworks: an example is shown in that quartz has no mode in the ranges corresponding to peaks \#2, \#3 and \#5. As a consequence, tridymite and quartz share many aspects particularly for the deformations for $\mathrm{Si}^{-} \mathrm{O}^{-} \mathrm{Si}$ bonds or $\mathrm{SiO}_{4}$ units, but the tridymites are richer in the variations of the bond-deformations or atom displacement patterns than quartz.

The success in simulating the experimental spectra gives a base on the given descriptions or discussions based on the frequencies of normal modes and atom polarization vectors. However, we remind that the ordered model of OP barely succeeded to simulate the experimental Raman spectra with the force parameters modified from those used successfully with the well-established structures of low quartz and even MC tridymite. This and the extremely large MSDs of $\mathrm{O}$ atoms may together suggest for the structure of OP to be more or less subjected to the disorder of atom positions.

A disorder model of the OP structure in Kihara (1995)'s geometrical study is briefly reviewed, and then improved to fit better to the experiments, i.e., the characteristic features of the thermal ellipsoids. In the geometrical study, the corner-linked $\mathrm{SiO}_{4}$ units are assumed to have the $\mathrm{Si}^{-} \mathrm{O}$ and $\mathrm{O}-\mathrm{O}$ lengths around 1.61 and $2.64 \AA$, respectively, but to be weakly deformable with the central

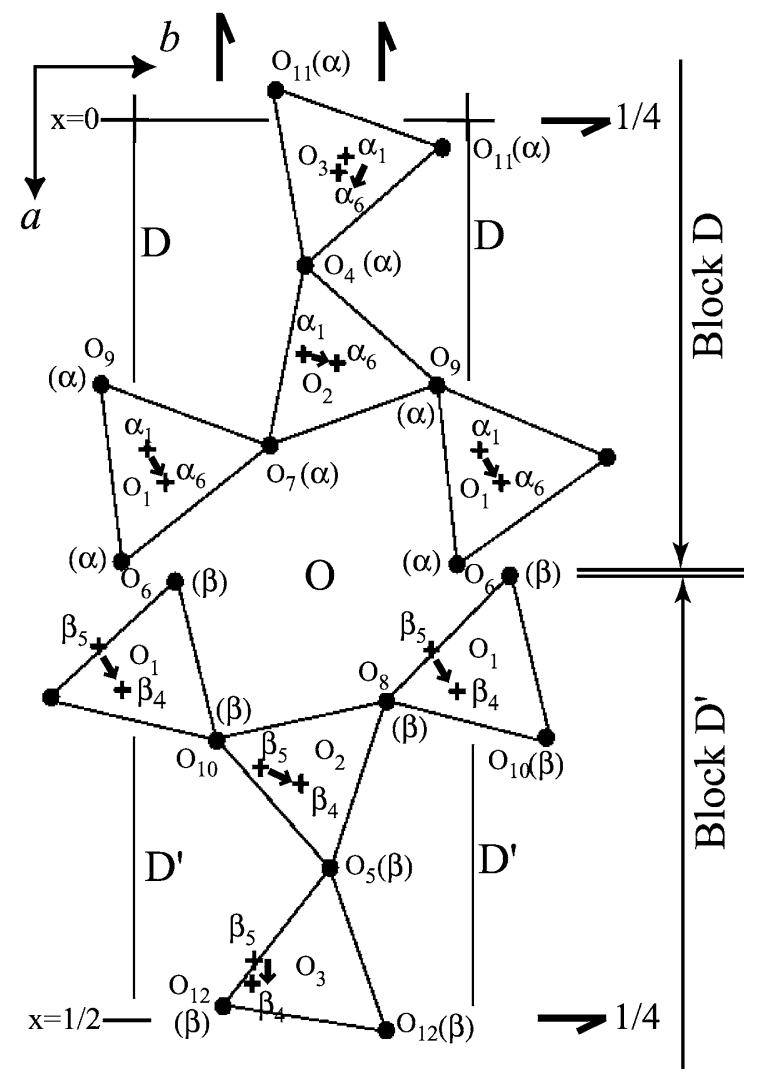

Figure 5. Possible orientations of corner-linked $\mathrm{SiO}_{4}$ units in a previous geometrical study of orthorhombic tridymite OP. A half of the unit-cell centering the boundary plane passing $\mathrm{O}_{6}$ sites is shown. Solid circles and plus signs indicate the positions of basal and apical O atoms, respectively, obtained in Kihara (1995). O atoms of $\mathrm{SiO}_{4}$ units appear in two separate volume elements at the basal $\mathrm{O}$ atom sites, each identified as a group of orientations: the two groups of orientations are represented with letters $\alpha$ and $\beta$. The $\alpha$ and $\beta$ groups are further divided into two groups $\alpha_{1}$ and $\alpha_{6}$, and $\beta_{5}$ and $\beta_{2}$, respectively. $\mathrm{SiO}_{4}$ units shown here are in two orientations $\alpha_{1}$ and $\alpha_{6}$ in the part from $x=0$ to $1 / 4$, and $\beta_{5}$ and $\beta_{4}$ from $x=1 / 4$ to $1 / 2$. Arrows at the apical $\mathrm{O}$ sites indicate vectors representing displacements from $\alpha_{1}$ to $\alpha_{6}$ in block D, and from $\beta_{5}$ to $\beta_{4}$ in block $\mathrm{D}^{\prime}$. 
$\mathrm{Si}$ atoms fixed on the positions of the $\mathrm{X}$-ray determined OP structure (with respect to the fractional coordinate system). The study showed some important points for the orientations of $\mathrm{SiO}_{4}$ units. Firstly, the possible orientations of the $\mathrm{SiO}_{4}$ units are limited to two groups, allowing each basal $\mathrm{O}$ atom to gather in one of two separate volume elements at the corresponding site. The two groups of orientations or positions are hereafter distinguished with letters $\alpha$ and $\beta$. We can see that the $\mathrm{D}^{-}$and $\mathrm{D}^{\prime}$-types of distortions (called as blocks $\mathrm{D}$ and $\mathrm{D}^{\prime}$ hereafter) result in the six-membered rings, if the $\mathrm{SiO}_{4}$ units take the orientations of group $\alpha$ in a half of the unit-cell, and of group $\beta$ in another half. Secondly, the $\mathrm{SiO}_{4}$ units in either orientation of group $\alpha$ or $\beta$ have their apical $\mathrm{O}$ atoms further in two groups referred as $\alpha_{1}$ and $\alpha_{6}$ or $\beta_{4}$ and $\beta_{5}$, respectively. Letters $\alpha_{1}, \alpha_{6}, \beta_{4}$ and $\beta_{5}$ identify not only the groups of the orientations of $\mathrm{SiO}_{4}$ units, but also the groups of the geometrically allowed positions of their $\mathrm{O}$ atoms: the subscript numbers follow Kihara (1995), where the six groups of the orientations of $\mathrm{SiO}_{4}$ units are examined. Figure 5 shows the half of the unit-cell including the boundary of the two blocks, D and D': solid circles and plus signs indicate the basal and apical $\mathrm{O}$ atoms, respectively, in orientation $\alpha_{1}$ from $x=0$ to $1 / 4$ and in orientation $\beta_{5}$ from $x=1 / 4$ to $1 / 2$. It is noted for the apical O sites that vectors $\alpha_{6}-\alpha_{1}$ (or $\alpha_{1}{ }^{-} \alpha_{6}$ ) in block $\mathrm{D}$ or $\beta_{4^{-}} \beta_{5}$ (or $\left.\beta_{5}-\beta_{4}\right)$ in block $\mathrm{D}^{\prime}$ are all with the same signs for the $x^{-}$ components in each block. In other words, the reorientations or orientation changes of $\mathrm{SiO}_{4}$ units, $\alpha_{6} \rightarrow \alpha_{1}\left(\alpha_{6} \leftarrow\right.$ $\left.\alpha_{1}\right)$ or $\beta_{4} \rightarrow \beta_{5}\left(\beta_{4} \leftarrow \beta_{5}\right)$, take place, not inside the block $\mathrm{D}$ or $\mathrm{D}^{\prime}$, but at the boundaries of the blocks, in the disorder (irrespective of static or dynamic). The geometrical approach succeeded to reproduce the characteristic deformations of the six-membered rings into types $\mathrm{D}$ and $\mathrm{D}^{\prime}$. However, as seen in Figure 5, the model shows gaps at the interfaces between blocks D and $\mathrm{D}^{\prime}$, and some of vectors $\alpha_{6}-\alpha_{1}$ and $\beta_{5}-\beta_{4}$ at the apical $\mathrm{O}$ sites are considerably deviated from the corresponding directions of the longest principal axes of the thermal ellipsoids (not shown in this paper, but almost exactly represented with the polarization vectors shown in Figure 1a). Consequently we consider that the disordered structure concerned is not just as given in the geometrical study, but should be adjusted for the atom positions to relieve the gaps and to be more parallel with the experiments, i.e., the characteristic features in the MSDs. The disorder model may be renewed that the two orientations $\alpha_{6}$ and $\alpha_{1}$ in block D and $\beta_{4}$ and $\beta_{5}$ in block $\mathrm{D}^{\prime}$ are allowed for the nearly rigid corner-linked $\mathrm{SiO}_{4}$ units, where each couple of orientations $\alpha_{6}{ }^{-} \alpha_{1}$ and $\beta_{4}{ }^{-} \beta_{5}$ is related by the rotations around the axes, which pass the central $\mathrm{Si}$ atoms and are nearly parallel with [010] for all the $\mathrm{SiO}_{4}$ units.
There is no evidence identifying our disorder to the dynamical one reported in Xiao et al. (1995)'s NMR study. If the disorder is static, orientation changes $\alpha_{6} \rightarrow \alpha_{1}$ (or $\alpha_{6} \leftarrow \alpha_{1}$ ) and $\beta_{4} \rightarrow \beta_{5}$ (or $\beta_{4} \leftarrow \beta_{5}$ ) should occur at some boundaries of the blocks to form static domains. We here consider the possibility of a dynamical disorder, i.e., the corner-linked $\mathrm{SiO}_{4}$ units reorient with time over the energy barriers between $\alpha_{6}$ and $\alpha_{1}$, or between $\beta_{4}$ and $\beta_{5}$ involving the entire body of either block $\mathrm{D}$ or $\mathrm{D}^{\prime}$. This disorder may be of much lower frequencies than those of normal mode phonons, and both the kinds of motions should be essentially independent of each other. That is to say, during the $\mathrm{SiO}_{4}$ units stay in one of the two orientations, the atoms independently undergo normal-mode vibrations there. Even in such a condition, we assume that some couplings are possible between some normal modes and the dynamical reorientations of the $\mathrm{SiO}_{4}$ units. In this regard, we refer to a much simpler but similar relation between disorder and a normal mode in low quartz, indicated in a molecular dynamics study (Kihara, 2001). In quartz, two potential energy minima $\alpha_{\mathrm{A}}$ and $\alpha_{\mathrm{B}}$, related by Dauphiné twinning (or, in other words, by the rotation of the $\mathrm{SiO}_{4}$ units around the $<100>$ axes passing the central Si atoms) with distance about $0.8 \AA$, are reserved for every $\mathrm{O}$ atom. In the $216 \mathrm{~cm}^{-1} A_{1}$ mode at $\Gamma$ of low quartz, well known as the soft mode of the $\alpha^{-} \beta$ transition, the polarization vectors of all the atoms occupying one of the Dauphiné-twin related positions, say $\alpha_{\mathrm{A}}$, are directed toward their corresponding $\alpha_{\mathrm{B}}$ positions. The disordering motions over $\alpha_{\mathrm{A}}$ and $\alpha_{\mathrm{B}}$ are symmetrically compatible with those in the $A_{1}$ mode. In the molecular dynamics study, atoms begin to move over the energy barriers toward their Dauphiné-twin related positions and then back to the original positions at temperatures even below the $\alpha-\beta$ transition temperature. The disordering motions are apparently triggered by the low frequency mode. Returning to OP tridymite, the $B_{3}$ normal mode at $74.9 \mathrm{~cm}^{-1}(2.25 \mathrm{THz})$ is worthy of notice: it has the polarization vectors for $\mathrm{O}$ atoms (Fig. 1a), not only symmetrically compatible with, but also nearly parallel with vectors $\alpha_{6}-\alpha_{1}$ (or $\alpha_{1}^{-} \alpha_{6}$ ) in block D or $\beta_{5^{-}} \beta_{4}$ (or $\beta_{4^{-}} \beta_{5}$ ) in $\mathrm{D}^{\prime}$ (in the renewed disorder model). We remind that the MSDs in the longest principal axes of the thermal ellipsoids for $\mathrm{O}_{1}, \mathrm{O}_{2}, \mathrm{O}_{3}, \mathrm{O}_{4}$ and $\mathrm{O}_{5}$ in $\mathrm{OP}$ are in the range of 0.15 to $0.18 \AA^{2}$ around the average of $0.165 \AA^{2}$, i.e., about $0.4 \AA$ in RMS amplitudes. The twice of this RMS amplitude, $0.8 \AA$, happens to agree with the $\alpha_{\mathrm{A}^{-}} \alpha_{\mathrm{B}}$ separation for the $\mathrm{O}$ atoms in quartz. This leads us to consider that the corner-linked $\mathrm{SiO}_{4}$ units in tridymite can also undergo the disordering motions, likely in low quartz. The 74.9 $\mathrm{cm}^{-1}\left(B_{3}\right)$ mode at the $\Gamma$-point may be one of the most probable ones being able to trigger the reorientations of 
all the $\mathrm{SiO}_{4}$ units in a block, as the $216 \mathrm{~cm}^{-1} A_{1}$ mode in quartz. If each block can take a possible orientation freely or nearly freely from the next ones, the $\mathrm{B}_{3}$ mode may boost all the blocks in the crystal to reorient as $\alpha_{6} \rightarrow \alpha_{1}$ for block D and $\beta_{5} \rightarrow \beta_{4}$ for block $\mathrm{D}^{\prime}$ and vice versa. Interactions between the orientations of $\mathrm{SiO}_{4}$ units in neighboring blocks should be weak for the $B_{3}$ mode to induce and extend the $B_{3}$-adapted reorientations over the crystal. In taking account of the case for low quartz, we consider it possible for some normal modes to assist the dynamical reorientations of $\mathrm{SiO}_{4}$ units in OP.

\section{CONCLUDING REMARKS}

The valence-force field of Etchepare (1974), successfully used in quartz, is also successful for both MC and OP tridymites with some parameter-values changed. The calculated normal modes with frequencies and polarization vectors keep the essential features unchanged in the two phases, and reasonably reflect the differences in their structural details. In OP, the apical $\mathrm{O}$ atoms show different behaviors from those for other $\mathrm{O}$ atoms in many cases of normal modes especially with low frequencies. The essential features in the atom displacements or bond deformations in the normal modes in tridymite are also comparable with those in quartz.

The bond deformations in relatively high frequencies (above $700 \mathrm{~cm}^{-1}$ ) in these tridymites are conveniently classified into the 10 types, of which seven are for $\mathrm{Si}^{-} \mathrm{O}^{-}$ $\mathrm{Si}$ and three are for $\mathrm{SiO}_{4}$. Most of the seven types for $\mathrm{Si}^{-}$ $\mathrm{O}-\mathrm{Si}$ are comparable with the deformation patterns of simple three-atom molecules such as $\mathrm{H}_{2} \mathrm{O}$. The highest frequency group of modes $\left(1150-1250 \mathrm{~cm}^{-1}\right)$ involves the symmetric stretching or compressions of the $\mathrm{Si}^{-} \mathrm{O}$ bonds of each $\mathrm{SiO}_{4}$ unit.

A disorder model for OP tridymite, which was basically obtained in the previous geometrical study, is modified, in taking account of a low-frequency normal mode, to account for the extremely large MSDs of $\mathrm{O}$ atoms determined in $\mathrm{X}$-ray studies. The basic feature of the disorder is that the corner-linked $\mathrm{SiO}_{4}$ units can take two orientations related by the rotations around the axes, all nearly parallel with [010], passing the central $\mathrm{Si}$ atoms. At least for the symmetry point of view, a low-frequency (about $75 \mathrm{~cm}^{-1}$ ) $B_{3}$ mode at the $\Gamma$-point could trigger or boost the reorientation-motions of $\mathrm{SiO}_{4}$ units extending through the whole part of the crystal.

\section{ACKNOWLEDGMENTS}

We express sincere thanks to Dr. K. Sakai of Asahi Glass Co., who gave us good quality tridymite samples. This study was supported by the Grant-in-Aid for Scientific Research (C) of JSPS (\#14540446).

\section{REFERENCES}

Dowty, E. (1987) Fully automated microcomputer calculation of vibrational spectra. Physics and Chemistry of Minerals, 14, 67-69.

Etchepare, J., Merian, M. and Smetankine, L. (1974) Vibrational normal modes of $\mathrm{SiO}_{2} . \alpha$ and $\beta$ quartz. Journal of Chemical Physics, 60, 1873-1876.

Etchepare, J., Merian, M. and Kaplan, P. (1978) Vibrational normal modes of $\mathrm{SiO}_{2}$. II. Cristobalite and tridymite. Journal of Chemical Physics, 68, 1531-1537.

Hirose, T, Kihara, K., Okuno, M., Fujinami, S. and Shinoda, K. (2005) X-ray, DTA and Raman studies of monoclinic tridymite and its higher temperature orthorhombic modification with varying temperature. Journal of Mineralogical and Petrological Sciences. (Submitted).

Kihara, K. (1977) An orthorhombic superstructure of tridymite existing between about 105 and $180^{\circ} \mathrm{C}$. Zeitshrift für Kristallographie, 146, 185-203.

Kihara, K. (1980) On the split-atom model for hexagonal tridymite. Zeitshrift für Kristallographie, 152, 95-101.

Kihara, K. (1995) Disorder and successive structure transitions in the tridymite forms of $\mathrm{SiO}_{2}$. Physics and Chemistry of Minerals, 22, 223-232.

Kihara, K. (2001) Molecular dynamics interpretation of structural changes in quartz. Physics and Chemistry of Minerals, 28, 365-376.

Kihara, K. Matsumoto, T. and Imamura, M. (1986) Structural change of orthorhombic-I tridymite with temperature: A study based on second-order thermal-vibrational parameters. Zeitshrift für Kristallographie, 177, 27-38.

Nieuwenkamp, W. (1937) Über die Struktur von Hoch-Cristobalit. Zeitshrift für Kristallographie, 96, 454-458.

Nukui, A. and Nakazawa, H. (1978) Thermal changes in monoclinic tridymite. American Mineralogist, 63, 1252-1259.

Nukui, A. and Nakazawa, H. (1980) Polymorphism in tridymite. Journal of Mineralogical Society of Japan, 14, Special volume 2, 364-386.

Peacor, D. (1973) High-temperature single-crystal study of the cristobalite inversion. Zeitshrift für Kristallographie, 138, 274-298.

Xiao, Y. Kirkpatrick, R.J. and Kim, Y.J. (1993) Structural phase transitions of tridymite: A ${ }^{29} \mathrm{Si}$ MAS NMR investigation. American Mineralogist, 78, 241-244.

Manuscript received May 182004

Manuscript accepted December 10, 2004

Manuscript handled by Takashi Murakami 